\title{
Optimization of a Hybrid Carbon/Glass Composites Afterbody of the Amphibious Plane with Finite Element Analysis
}

\author{
Mongkol Thianwiboon* \\ Department of Industrial Engineering, Faculty of Engineering, Mahidol University, Nakorn Pathom 73170, \\ Thailand \\ E-mail: *mongkol.thi@mahidol.ac.th (Corresponding author)
}

\begin{abstract}
The main objective of this research is to find the optimized lay up for the afterbody of the amphibious plane which can carried load according to ASTM F2245 (Standard Specification for Design and Performance of a Light Sport Airplane).

The finite element analyses of hybrid carbon/glass composites are carried out using ANSYS ACP under assumption that the hybrid carbon/glass fiber composites could combine the strong sides of carbon and glass fiber reinforced polymer to balance between strength, weight and cost to achieve the requirement for each design of the aircraft.

While the stress of the carbon and glass fiber in the structure are within the safety limit, the results show that the weight is minimum when the laminate ply pattern consists of 3.18 $\mathrm{mm}$ foam core (D) sandwiched by 3 layers of carbon woven fabrics on both side $\left[( \pm 45)_{C}(0 / 90)_{C}( \pm 45)_{C} \bar{D}\right]_{S}$. While the laminate ply pattern with $3.18 \mathrm{~mm}$ foam core sandwiched by 2 layers of carbon and 1 layer of glass woven fabric $\left[( \pm 45)_{C}(0 / 90)_{C}( \pm 45)_{G} \bar{D}\right]_{S}$ on both side have a good balance between weight and cost.
\end{abstract}

Keywords: Composite material, hybrid carbon/glass fiber composites, light sport aircraft, composite fuselage, FEA.

ENGINEERING JOURNAL Volume 23 Issue 5

Received 4 June 2019

Accepted 5 July 2019

Published 30 September 2019

Online at http://www.engj.org/

DOI:10.4186/ej.2019.23.5.125 


\section{Introduction}

The aircraft in this study is designed as a seaplane made of composite materials with wing span $9700 \mathrm{~mm}$ (excluding wing tip), overall length $6650 \mathrm{~mm}$ and maximum takeoff weight $650 \mathrm{~kg}$. Its structure are designed based on FAR Part 23 (Airworthiness Standards for a Utility Category Airplanes) and ASTM F2245 (Standard Specification for Design and Performance of a Light Sport Airplane).

This seaplane also equipped with retractable landing gear making it an amphibious aircraft which can land either on land or on water. The CAD model of this aircraft with the landing gear in deployed position is shown in Fig. 1. The bottom half of the fuselage is specifically designed to acts as a hull for operation on the water $[1,2,3]$. The hull is divided into forebody and afterbody by a transverse main step [4]. The edge of the step is placed slightly aft of the CG [5], and the height of the step is typically approximately 2.5 to 8 percent of the hull beam $[5,6]$. Two transverse steps have sometimes been employed in the design of the seaplane hull [7].
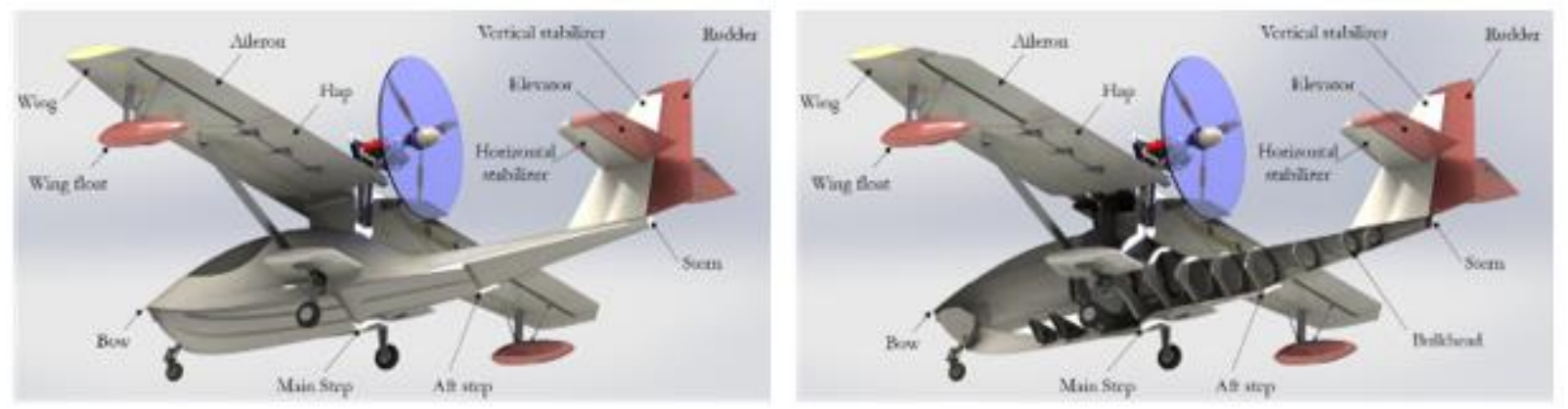

Fig. 1. CAD model with landing gear in deployed position.

The step separates the water from the fuselage skin during takeoff by forming an air pocket behind it, which leads to a reduction in suction. As the speed of the aircraft increases, this air pocket begins to extend toward the stern and separate the aft of the hull from the water. A slight forward pitch cause the after body to lift and clear of the water. At this stage, most of the seaplane's weight is supported by hydrodynamic lift rather than the buoyancy (Fig. 2). The water drag is greatly reduced, allowing the seaplane to accelerate and skim to takeoff speed. This position is called "on the step" [2, 4].

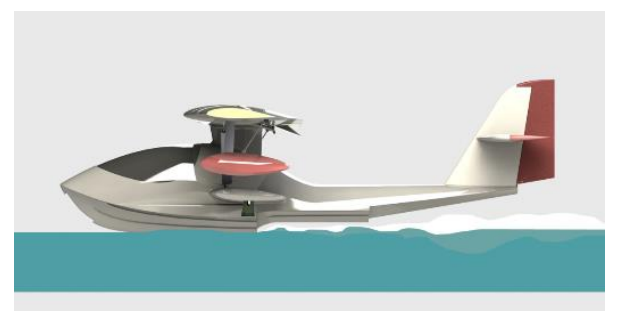

Fig. 2. The plane is skimming with attitude is nearly level. The hydrodynamic lift supported most of the weight. The afterbody is clear of water.

Without the step, most seaplanes will lack sufficient power to accelerate to takeoff speed. Anyway, this surface discontinuity increases the aerodynamic drag of the seaplane [1] and also induce stress concentrations around the step. Thus, the step is naturally weak point of the fuselage when subject to the aerodynamic load from the empennage and load during landing.

The empennage of the seaplane in this study consists of the fuselage afterbody integrated with the vertical and horizontal tail. The vertical and horizontal tails consist of fixed aerodynamic surfaces, such as the vertical stabilizer, the horizontal stabilizer and the movable aerodynamic surfaces, such as the rudder and the elevator $[8,9]$. The fuselage is designed as a monocoque structure combining a stressed skin and bulkheads made of composite materials as shown in Fig. 1. but the afterbody structure is lighter since it receive less stress [3, 10]. 
The fuselage and the bulkheads (BH) are shown in Fig. 1 and 3. Each bulkhead consists of the web and flanges as shown in Fig. 4. The outer and inner flange are designated as rim and collar respectively.

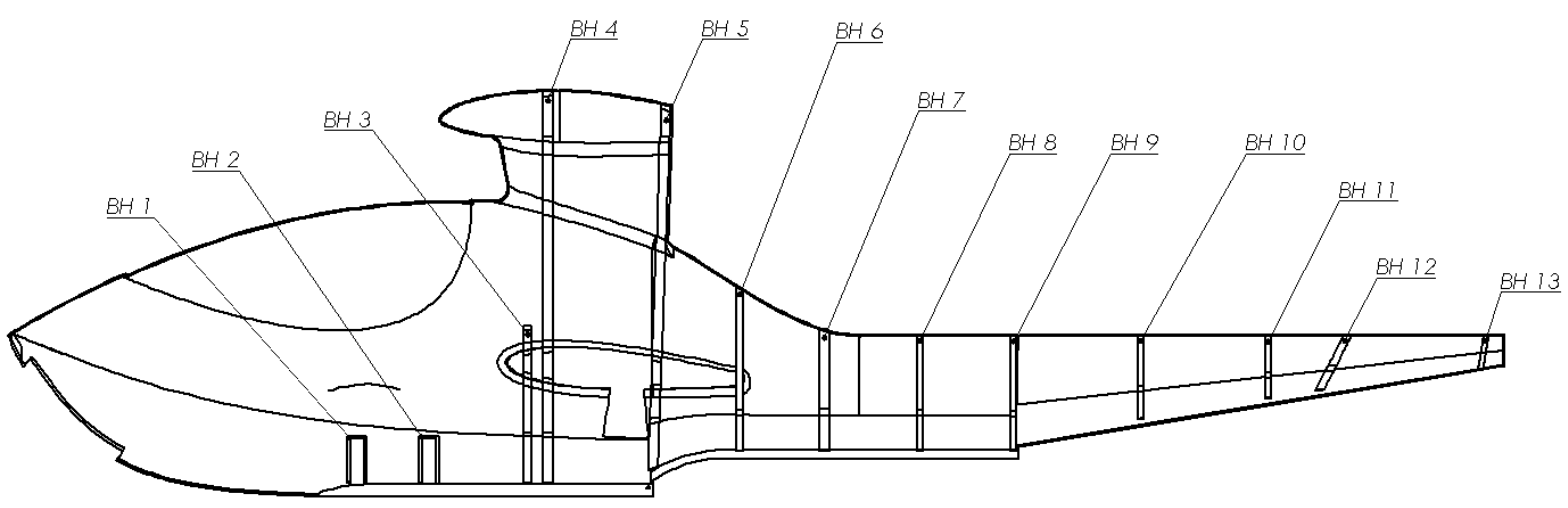

Fig. 3. Bulkheads inside the fuselage.

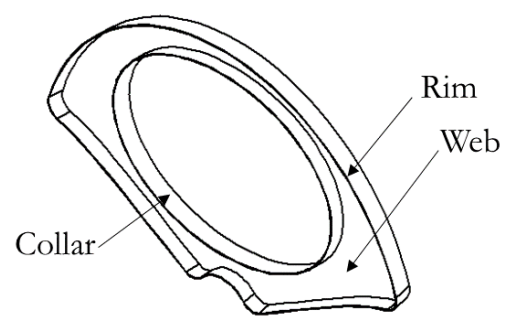

Fig. 4. Bulkhead components.

In this paper, the finite element analyses of hybrid carbon/glass composites are carried out in ANSYS ACP to find the suitable ply pattern which can compromise between weight and cost in a light sport airplane with limited weight according to the standard. The study also provided some useful data, which serve as a guideline for the future design or detailed design.

\section{Literature Review}

Composite materials are a combination of two or more materials which are reinforcements (fiber) bonded together with the matrix (resin). By combining the best properties from each material, the composites can achieve the best characteristics that neither of the constituent materials could achieve on their own $[11,12$, 13]. Composites materials are typically built up by embedding the individual plies of fibers into a polymer matrix layer-by-layer [14]. Due to the laminated nature of composites, the stiffness and strength are changed with the orientation of fiber. The optimum properties can be achieve by orienting the fiber direction with the direction of primary load $[14,15]$.

Composite materials are increasingly used in aerospace applications due to high strength-to-weight and stiffness-to-weight ratio, high corrosion resistance and resistance to damage from fatigue [11, 16]. Furthermore, composites material have a capability to be formed into large and integrate structure such as wing and fuselage $[17,18,19]$. The traditional E-type glass fiber composites provide adequate strength with low cost and suitable for interiors or small parts that do not have to carry heavy loads or stress [20,21, 22]. The interest to stronger and lighter carbon fibers is growing in applications where a small amount of flexibility is allowed due to its stiffness. However, the carbon fiber have higher price (about 8x-10x of E-glass) and relatively low on compression strength while the glass fiber has lower tensile modulus, higher strain-to-failure, able to flex and take more strain without shattering. Carbon fiber are also more sensitive to fiber misalignment from manufacturing process. [15]. Then the hybrid composites containing both carbon and glass fibers attracted an interest of industries and scientists. It is expected that the hybrid composites, made by embedding carbon and glass fibers into common matrix, could combine the strong sides of glass and carbon fibers and compensating their weakness. [23, 24]. 
Mander and Bader studied hybrid effect and strain enhancement for the hybrid carbon/glass fiber composite. The failure strain is increased as the proportion of glass fiber was increased due to glass fiber has higher elongation [25]. From the studies of Shan et al. The hybrid composites has better fatigue behavior both in air and water compared with all-glass composites [26, 27]. The analysis of bending fatigue stiffness in hybrid composites carried out by Belingardi and Cavatorta [28], a configuration with carbon fibers at the exterior and E-glass in the core provides superior bending fatigue properties. Cavatorta also stated that the strength of the structure is dominated by the outer carbon fibers [29]. Pui-yan Hung studied also shown that using carbon fibers as top and bottom layers helps reduce the size and defection of damage, as the flexural strength is controlled by the strength of the bottom layer [30].

Zhang et al. experiments found that the stacking sequence did not show noticeable influence on the tensile properties but significantly affected the flexural and compressive properties. The hybrid composites exhibited more matrix failure under flexural loading and more reinforcement failure under compressive loading [31]. It is shown that the hybrid composites with $50 \%$ carbon fiber provide best flexural properties when the carbon layers are at exterior, consistent with previous analysis by Cavatorta. The alternating carbon/glass stacking provides the highest compressive strength [32]. Thirumalai et al. comparative study of the hybrid composites shown that strain to failure of the carbon/epoxy specimens are less than the glass/epoxy specimens consistent with Mander and Bader studies. For hybrid composites, the tensile and compressive properties fall between non-hybrid carbon/epoxy and glass/epoxy composites [33].

The hybrid have high potential for using as highly durable and damage resistant materials. However, their performances depend on a number of microstructural and loading parameters, and these effects should be analyzed both experimentally and theoretically [34]. The mechanical properties is often simply obtained by using a general rule of mixtures (RoM). However, Chensong Dong research shows that hybrid effects exist. The properties obtained from RoM differs from that observed in reality. Large variations in the flexural properties exist in carbon/glass fiber reinforced epoxy hybrid composites [35]. Buddi et al. compare the experiment results with the RoM and Halphin-Tsai criteria and found that the finite element model can be used to predict the properties of composites [36]. Dulgheru et al. research found that the error from the simulation with ANSYS APDL is about $20 \%$ compare to the experiments [37].

To achieve the optimum design of the structures, the finite element method can be used conjunction with the optimization techniques to find the best candidate which meet the specific design requirements. In 2011, Wei-XinRen et al. studied the feasibility to use the response surface methodology with finite element structural analysis. By fitting and evaluating with a simple beam case and extend to a more complex case [38]. Venkatesh et al. also implemented the FEM with the design optimization of the truck chassis [39]. Cayiroglu and Kilic used genetic algorithm and ANSYS Fluent to optimize the wing aerodynamic in 2017. However the limitation of the algorithm is computationally expensive and design variable can be determined only in narrow limits [40]. Ozroy and Kurmaz introduced an alternative approach by using Design of Experiments (DoE) and Response Surface technique with FEM to obtain three best candidates then finally select one candidate for manufacturing [41].

\section{Material Data Validation}

The skins of the fuselage and bulkhead web of the seaplane in this research are sandwich composites with glass and carbon woven fabric and low density foam core (Divinycell ${ }^{\circledR}$ HT61 by DIAB Inc.). The specimens are prepared according to ASTM D3039/D3039M-14 and ASTM D3518-D3518M-18 (Standard Test Method for Tensile Properties of Polymer Matrix Composite Materials and Standard Test Method for InPlane Shear Response of Polymer Matrix Composite Materials by Tensile Test of a $\pm 45^{\circ}$ Laminate, respectively) and testing on Instron 5567 Universal testing machine. The $0 / 90$ carbon woven specimens are shown in Fig. 5. Failure of the specimens submitted to tensile tests are shown in Fig. 6.

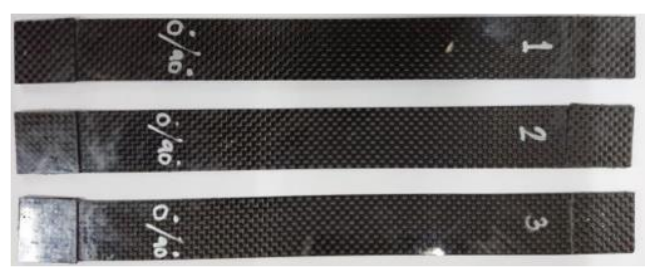

Fig. 5. The $0 / 90$ carbon woven specimens. 


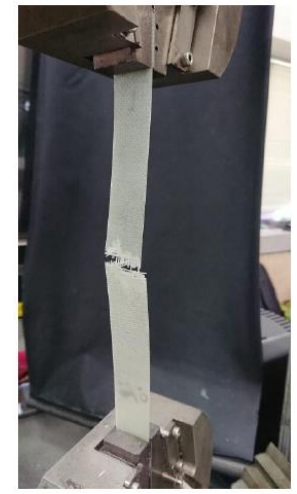

(a) $0 / 90$ glass woven

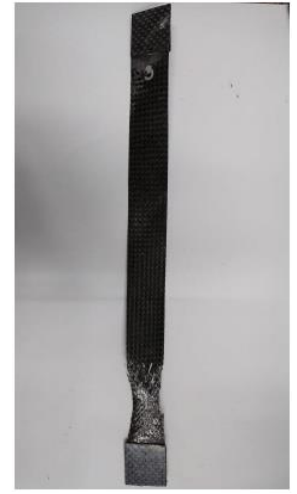

(b) \pm 45 carbon woven

Fig. 6. Failure of the specimens submitted to tensile tests.

Afterthat, the material properties from the testing are input into ANSYS database and validated with the results from the experiments similar to Dulgheru, Bostan and Marin [37] research with the axes convention shown in Fig. 7.

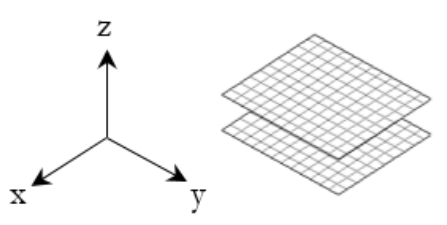

Fig. 7. Axes convention for material properties.

Cost of the materials are gathered from the aircraft manufacturer, Asia Aviation and Technology (AAT), during manufacturing period between 2016-2018. Summary of the material properties and cost used in the fuselage and bulkheads are shown in Table 1.

Table 1. Summary of the material properties and cost used in the experiments.

\begin{tabular}{lcccc}
\hline Property & Symbol & $\begin{array}{c}\text { Carbon } \\
\text { woven / } \\
\text { epoxy }\end{array}$ & $\begin{array}{c}\text { Glass } \\
\text { woven / } \\
\text { epoxy }\end{array}$ & $\begin{array}{c}\text { Divinycell® } \\
\text { HT61 }\end{array}$ \\
\hline Modulus of Elasticity $(\mathrm{MPa})$ & $\mathrm{E}_{11}$ & 36590 & 11580 & 75 \\
Shear Modulus $(\mathrm{MPa})$ & $\mathrm{G}_{12}$ & 2405 & 2030 & 20 \\
Tensile X, Y direction $(\mathrm{MPa})$ & $\sigma_{\mathrm{x}}, \sigma_{\mathrm{y}}$ & 395 & 160 & 1.8 \\
Tensile Z direction $(\mathrm{MPa})$ & $\sigma_{\mathrm{z}}$ & 38.5 & 6.35 & 1.8 \\
Shear XY $(\mathrm{MPa})$ & $\tau_{\mathrm{xy}}$ & 49.3 & 37.9 & 0.9 \\
Shear XZ, YZ $(\mathrm{MPa})$ & $\tau_{\mathrm{xz}}, \tau_{\mathrm{yz}}$ & 22.6 & 22.1 & 0.9 \\
Poisson's ratio & $\mathrm{v}_{12}$ & 0.285 & 0.285 & 0.5 \\
Density & $\varrho$ & 1.431 & 1.539 & 0.065 \\
Cost $\left(\mathrm{USD} / \mathrm{m}^{2}\right)$ & & 19.7 & 1.5 & $51(6.35 \mathrm{~mm})$ \\
& & & & $34.7(3.18 \mathrm{~mm})$ \\
\hline
\end{tabular}

\section{Afterbody Simulations}

\subsection{Location and Magnitude of Loads}

The coordinate system convention used for most aircrafts is based on XYZ system consists of fuselage station (FS), water line (WL) and buttock line (BL). The fuselage station (FS) designate location from the reference 
datum along the length of the aircraft, positive pointing aft. The water line (WL) is the measurement of height from a horizontal plane usually located at the ground or the bottom of the fuselage. The buttock line (BL) designate location left/right, positive pointing along the plane's right wing [3]. For the seaplane in this study, the FS0, WL0 and BL0 are located at the nose tip, at the bottom of the fuselage and at the aircraft plane of symmetry respectively.

According to ASTM F2245, the horizontal stabilizer load consists of balancing loads, maneuvering loads and gust loads. While the vertical stabilizer is subjected to maneuvering loads and gust loads. The afterbody must be able to support loads from these control surfaces without detrimental and permanent deformation. ASTM F2245 also stated that the factor of safety of 1.5 must be used for ultimate load.

The aerodynamic loads were applied at the aerodynamic center of each control surfaces. For most standard airfoil, the aerodynamic center is close to a location $1 / 4$ chord back from the leading edge [42, 43]. The location of loads are shown in Fig. 8 and Table 2.

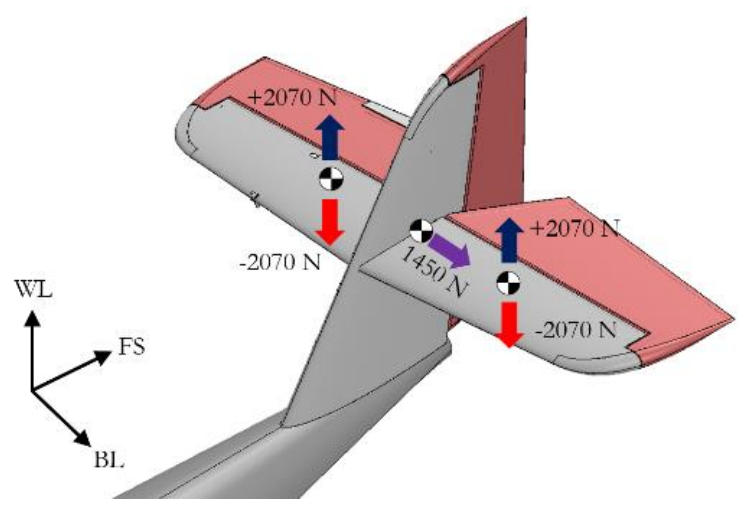

Fig. 8. Location of aerodynamic loads on the seaplane tail.

Table 2. Magnitude and location of aerodynamic loads on the control surfaces.

\begin{tabular}{lcccc}
\hline Control surfaces & $\begin{array}{c}\text { Magnitude } \\
(\mathbf{N})\end{array}$ & $\begin{array}{c}\text { FS } \\
(\mathbf{m m})\end{array}$ & $\begin{array}{c}\text { WL } \\
(\mathbf{m m})\end{array}$ & $\begin{array}{c}\text { BL } \\
(\mathbf{m m})\end{array}$ \\
\hline Vertical stabilizer & 1450 & 5832 & 1280 & 0 \\
Left horizontal stabilizer & 2070 & 5832 & 1280 & 663 \\
Right horizontal stabilizer & 2070 & 5832 & 1280 & -663 \\
\hline
\end{tabular}

Additional to aerodynamic loads, the afterbody also subjected to the load from weight of the empennage approximately $200 \mathrm{~N}$ and weight of itself due to gravitational acceleration.

\subsection{Laminate Ply Pattern of the Bulkheads}

Since the composite materials with carbon fibers at the outer layers shown superior properties compare to E-glass $[28,29,30]$, in all parts, the \pm 45 carbon fibers fabric were layup as the outer layer in laminate ply pattern. The laminate ply pattern of the bulkhead webs and collars are shown in Table 3 and Fig. 9.

Table 3. Laminate definition of the bulkhead no.6 to 13.

\begin{tabular}{lccc}
\hline Bulkhead no. & Bulkhead component & No. of plies & Ply pattern \\
\hline 6 & Web & 5 & {$\left[( \pm 45)_{C}(0 / 90)_{C} \bar{D}\right]_{S}$} \\
$7-13$ & Web & 5 & {$\left[( \pm 45)_{C}(0 / 90){ }_{C} \bar{D}\right]_{S}$} \\
$7-13$ & Collar & 4 & {$\left[( \pm 45)_{C}(0 / 90){ }_{C}\right]_{S}$} \\
\hline
\end{tabular}

C : carbon fiber fabric; G : glass fiber fabric; D : Divinycell foam core; S : symmetry. Symmetric laminates with an even number of plies are represented by listing all plies on one side of the mid-plane enclosed in 
brackets, followed by the subscript "S". Symmetric laminates with an odd number of plies are listed with a bar over the center ply to indicate it is the mid-plane.

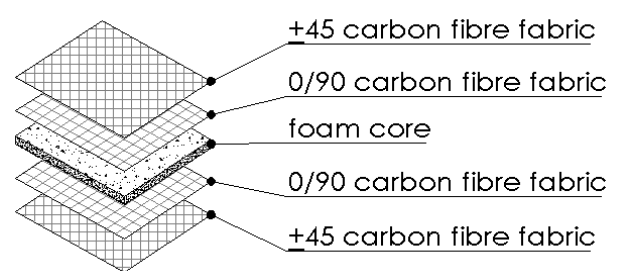

(a) Web

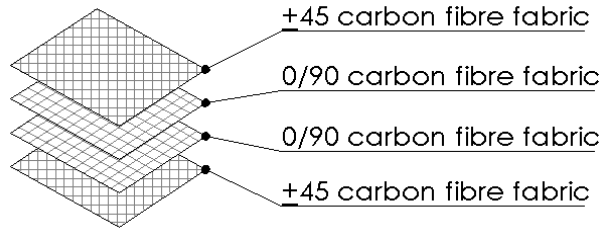

(b) Collar

Fig. 9. The laminate ply patterns of the bulkhead components.

\subsection{Simulation Setup}

The geometric model of the seaplane afterbody was created as a shell models as shown in Fig. 10. The element are quadrilateral dominant with global size $15 \mathrm{~mm}$. Mesh refinement has been specified to $8 \mathrm{~mm}$ at the step area for better accuracy. Total number of the elements in this model is 28928 elements. The model consists of the fuselage skin reinforce with bulkhead no.6 to 13. The locations of the bulkheads are shown in Table 4.

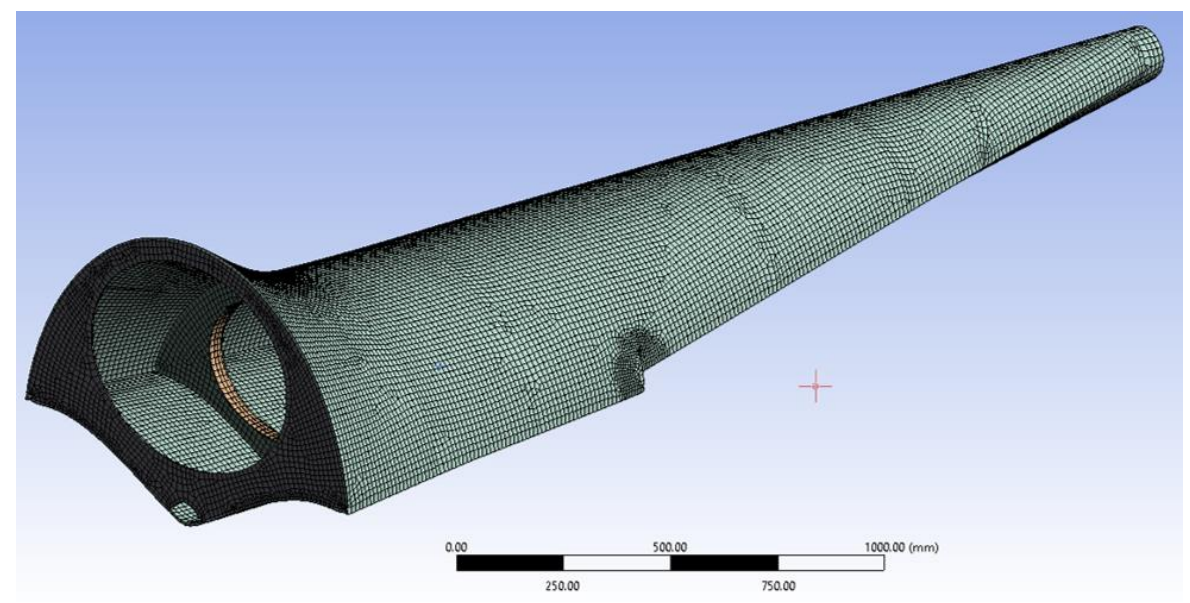

Fig. 10. Shell model of the afterbody.

Table 4. Fuselage station of the bulkhead no.6 to 13.

\begin{tabular}{cc|cc}
\hline Bulkhead no. & FS $\mathbf{( m m )}$ & Bulkhead no. & FS (mm) \\
\hline 6 & 3019 & 10 & 4667 \\
7 & 3375 & 11 & 5190 \\
8 & 3753.3 & 12 & 5407.5 \\
9 & 4144 & 13 & 6062.5 \\
\hline
\end{tabular}

Total 48 laminate ply patterns of the fuselage were set up into 2 subgroups, A and B, with foam core thickness $6.35 \mathrm{~mm}$ and $3.18 \mathrm{~mm}$ respectively. Table 5 shows the details of the ply patterns in each subgroup. For example, the ply pattern consists of 1 layer of carbon fiber and 2 layers of glass fiber with $6.35 \mathrm{~mm}$ core, this case is called A12. Figure 11 shows case A02, A12, B02 and B12 as examples. 


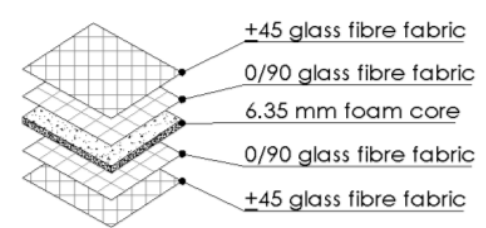

(a) case $\mathrm{A} 02$

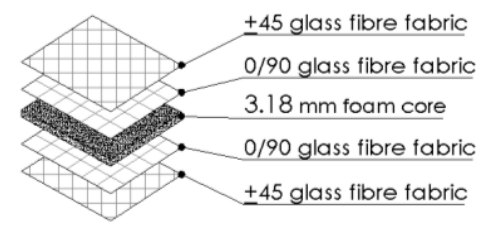

(c) case B02

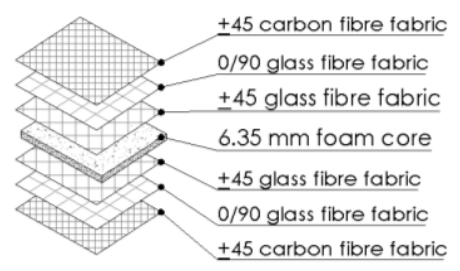

(b) case A12

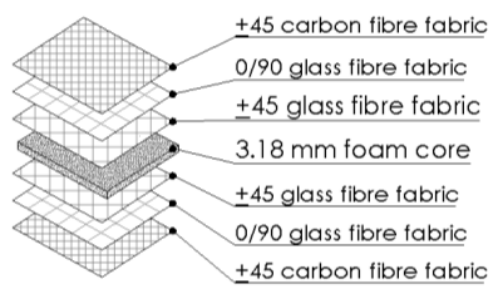

(d) case B12

Fig. 11. The laminate ply patterns of the fuselage shell.

Analysis of the composite shell model of the afterbody was done with Ansys Composite PrepPost (ACP) and Ansys Mechanical Module, using finite element method. For structural tests, the surface of bulkhead no. 6 was chosen as the fixed support and the gravitational acceleration was defined. The weight of the empennage was applied at the surface under vertical stabilizer as remote load. The aerodynamic loads on vertical stabilizer was applied with the magnitude and position specified in Fig. 8 and Table 2. The aerodynamic loads on both side of the horizontal stabilizer was applied with the magnitude specified in Table 2. But apply only one direction (up or down) at a time. For example, the downward forces were applied on both side of the horizontal stabilizer as shown in Fig. 12.

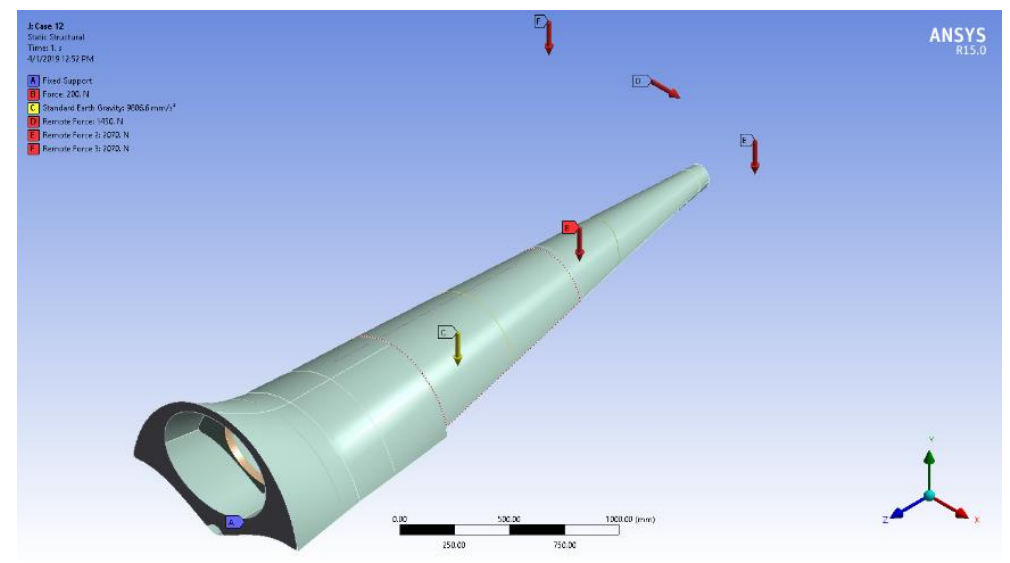

Fig. 12. Boundary and loading conditions. (A: Fixed support, B: Weight of the empennage, C: Gravitational acceleration, D: Aerodynamic loads on vertical stabilizer, E\&F: Aerodynamic loads in downward direction on horizontal stabilizers). 
Table 5. Laminate definition of the fuselage skin with foam core.

\begin{tabular}{|c|c|c|c|c|}
\hline \multirow{2}{*}{ no. } & \multirow{2}{*}{ Case } & \multicolumn{2}{|c|}{$\begin{array}{l}\text { no. of plies on one side } \\
\text { of the symmetry plane }\end{array}$} & \multirow{2}{*}{ Ply pattern } \\
\hline & & carbon fiber & glass fiber & \\
\hline 1 & 01 & 0 & 1 & {$\left[( \pm 45)_{G} \bar{D}\right]_{S}$} \\
\hline 2 & 02 & 0 & 2 & {$\left[( \pm 45)_{\mathrm{G}}(0 / 90)_{\mathrm{G}} \overline{\mathrm{D}}\right]_{\mathrm{S}}$} \\
\hline 3 & 03 & 0 & 3 & {$\left[( \pm 45)_{G}(0 / 90)_{G}( \pm 45)_{G} \bar{D}\right]_{S}$} \\
\hline 4 & 04 & 0 & 4 & {$\left[( \pm 45)_{\mathrm{G}}(0 / 90)_{\mathrm{G}}( \pm 45)_{\mathrm{G}}(0 / 90)_{\mathrm{G}} \overline{\mathrm{D}}\right]_{\mathrm{S}}$} \\
\hline 5 & 10 & 1 & 1 & {$\left[( \pm 45)_{C} \overline{\mathrm{D}}\right]_{S}$} \\
\hline 6 & 20 & 2 & 2 & {$\left[( \pm 45)_{C}(0 / 90)_{C} \bar{D}\right]_{S}$} \\
\hline 7 & 30 & 3 & 3 & {$\left[( \pm 45)_{C}(0 / 90)_{C}( \pm 45){ }_{C} \bar{D}\right]_{S}$} \\
\hline 8 & 40 & 4 & 4 & 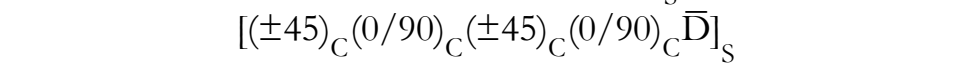 \\
\hline 9 & 11 & 1 & 1 & {$\left[( \pm 45)_{C}(0 / 90)_{G} \bar{D}\right]_{S}$} \\
\hline 10 & 12 & 1 & 2 & {$\left[( \pm 45)_{C}(0 / 90)_{G}( \pm 45)_{G} \bar{D}\right]_{S}$} \\
\hline 11 & 13 & 1 & 3 & {$\left[( \pm 45)_{\mathrm{C}}(0 / 90)_{\mathrm{G}}( \pm 45)_{\mathrm{G}}(0 / 90)_{\mathrm{G}} \overline{\mathrm{D}}\right]_{\mathrm{S}}$} \\
\hline 12 & 14 & 1 & 4 & {$\left[( \pm 45)_{C}(0 / 90)_{G}( \pm 45)_{G}(0 / 90)_{G}( \pm 45)_{G} \bar{D}\right]_{S}$} \\
\hline 13 & 21 & 2 & 1 & {$\left[( \pm 45)_{C}(0 / 90)_{C}( \pm 45)_{G} \bar{D}\right]_{S}$} \\
\hline 14 & 22 & 2 & 2 & {$\left[( \pm 45)_{C}(0 / 90)_{C}( \pm 45)_{G}(0 / 90)_{G} \bar{D}\right]_{S}$} \\
\hline 15 & 23 & 2 & 3 & {$\left[( \pm 45)_{C}(0 / 90)_{C}( \pm 45)_{G}(0 / 90)_{G}( \pm 45)_{G} \bar{D}\right]_{S}$} \\
\hline 16 & 24 & 2 & 4 & {$\left[( \pm 45)_{C}(0 / 90)_{C}( \pm 45)_{G}(0 / 90)_{G}( \pm 45)_{G}(0 / 90)_{G} \bar{D}\right]_{S}$} \\
\hline 17 & 31 & 3 & 1 & {$\left[( \pm 45)_{C}(0 / 90)_{C}( \pm 45)_{C}(0 / 90)_{G} \bar{D}\right]_{S}$} \\
\hline 18 & 32 & 3 & 2 & {$\left[( \pm 45)_{C}(0 / 90)_{C}( \pm 45)_{C}(0 / 90)_{G}( \pm 45)_{G} \bar{D}\right]_{S}$} \\
\hline 19 & 33 & 3 & 3 & {$\left[( \pm 45)_{C}(0 / 90)_{C}( \pm 45)_{C}(0 / 90)_{G}( \pm 45)_{G}(0 / 90){ }_{G} \bar{D}\right]_{S}$} \\
\hline 20 & 34 & 3 & 4 & {$\left[( \pm 45)_{C}(0 / 90)_{C}( \pm 45)_{C}(0 / 90)_{G}( \pm 45)_{G}(0 / 90)_{G}( \pm 45)_{G} \bar{D}\right]_{S}$} \\
\hline 21 & 41 & 4 & 1 & {$\left[( \pm 45)_{C}(0 / 90)_{C}( \pm 45)_{C}(0 / 90)_{C}( \pm 45)_{G} \bar{D}\right]_{S}$} \\
\hline 22 & 42 & 4 & 2 & {$\left[( \pm 45)_{C}(0 / 90)_{C}( \pm 45)_{C}(0 / 90)_{C}( \pm 45)_{G}(0 / 90)_{G} \bar{D}\right]_{S}$} \\
\hline 23 & 43 & 4 & 3 & {$\left[( \pm 45)_{C}(0 / 90)_{C}( \pm 45)_{C}(0 / 90)_{C}( \pm 45)_{G}(0 / 90)_{G}( \pm 45)_{G} \bar{D}\right]_{S}$} \\
\hline 24 & 44 & 4 & 4 & {$\left[( \pm 45)_{\mathrm{C}}(0 / 90)_{\mathrm{C}}( \pm 45)_{\mathrm{C}}(0 / 90)_{\mathrm{C}}( \pm 45)_{\mathrm{G}}(0 / 90)_{\mathrm{G}}( \pm 45)_{\mathrm{G}}(0 / 90)_{\mathrm{G}} \overline{\mathrm{D}}\right]_{\mathrm{S}}$} \\
\hline
\end{tabular}




\subsection{Simulation Results}

Total 80 structural analyses were conducted. (20 cases for $6.35 \mathrm{~mm}$ foam core and 20 cases for $3.18 \mathrm{~mm}$ foam. Each case apply load in upward and downward direction). The maximum stress in carbon fiber, glass fiber and maximum deformation are shown in Table 6. For example, the maximum stress in carbon fiber, glass fiber and maximum deformation of the case A12 are shown in Fig. 13 to 15 respectively.

Table 6. Maximum stress on carbon fiber, glass fiber and maximum deformation.

\begin{tabular}{|c|c|c|c|c|c|c|c|}
\hline $\begin{array}{c}(\mathrm{A}) \\
6.35 \mathrm{~mm} \\
\text { core }\end{array}$ & $\begin{array}{l}\text { Max. stress } \\
\text { on carbon } \\
\text { (MPa) }\end{array}$ & $\begin{array}{l}\text { Max. stress } \\
\text { on glass } \\
\text { (MPa) }\end{array}$ & $\begin{array}{c}\text { Max. } \\
\text { deform. } \\
(\mathrm{mm})\end{array}$ & $\begin{array}{c}\text { (B) } \\
3.18 \mathrm{~mm} \\
\text { core }\end{array}$ & $\begin{array}{c}\text { Max. stress } \\
\text { on carbon } \\
(\mathrm{MPa})\end{array}$ & $\begin{array}{l}\text { Max. stress } \\
\text { on glass } \\
\text { (MPa) }\end{array}$ & $\begin{array}{l}\text { Max. } \\
\text { deform. } \\
(\mathrm{mm})\end{array}$ \\
\hline A01 & - & 419.29 & 327.23 & B01 & - & 537.34 & 394.73 \\
\hline A02 & - & 245.92 & 146.44 & B02 & - & 292.85 & 172.43 \\
\hline A03 & - & 196.62 & 108.56 & B03 & - & 236.92 & 126.45 \\
\hline A04 & - & 156.96 & 80.74 & B04 & - & 192.19 & 93.26 \\
\hline A10 & 344.66 & - & 204.40 & B10 & 448.00 & - & 246.76 \\
\hline A20 & 245.19 & - & 61.88 & B20 & 288.47 & - & 71.77 \\
\hline A30 & 151.87 & - & 48.27 & B30 & 175.75 & - & 55.47 \\
\hline A40 & 141.71 & - & 34.74 & B40 & 160.67 & - & 39.45 \\
\hline A11 & 260.72 & 178.70 & 103.10 & B11 & 316.39 & 239.78 & 120.56 \\
\hline A12 & 214.98 & 149.53 & 84.69 & B12 & 258.81 & 193.44 & 97.73 \\
\hline A13 & 189.72 & 115.68 & 64.97 & B13 & 224.00 & 145.26 & 74.29 \\
\hline A14 & 163.55 & 103.53 & 57.24 & B14 & 205.66 & 117.89 & 60.98 \\
\hline A21 & 199.61 & 62.26 & 54.47 & B21 & 233.40 & 71.40 & 62.49 \\
\hline A22 & 184.47 & 57.44 & 46.90 & B22 & 214.13 & 65.53 & 53.36 \\
\hline A23 & 158.20 & 49.39 & 42.54 & B23 & 197.64 & 60.55 & 46.70 \\
\hline A24 & 148.60 & 46.37 & 37.91 & B24 & 170.02 & 52.25 & 42.43 \\
\hline A31 & 142.42 & 77.09 & 41.92 & B31 & 163.52 & 92.24 & 47.65 \\
\hline A32 & 126.71 & 71.31 & 38.53 & B32 & 152.92 & 80.14 & 41.94 \\
\hline A33 & 117.74 & 63.61 & 34.54 & B33 & 136.14 & 74.26 & 38.55 \\
\hline A34 & 106.60 & 59.65 & 32.18 & B34 & 122.61 & 68.92 & 35.65 \\
\hline A41 & 126.05 & 37.81 & 32.26 & B41 & 150.72 & 65.77 & 35.62 \\
\hline A42 & 117.08 & 35.29 & 29.56 & B42 & 134.31 & 38.97 & 33.00 \\
\hline A43 & 106.00 & 32.06 & 27.74 & B43 & 121.07 & 35.33 & 30.72 \\
\hline A44 & 101.11 & 30.64 & 25.72 & B44 & 114.60 & 33.63 & 28.27 \\
\hline
\end{tabular}




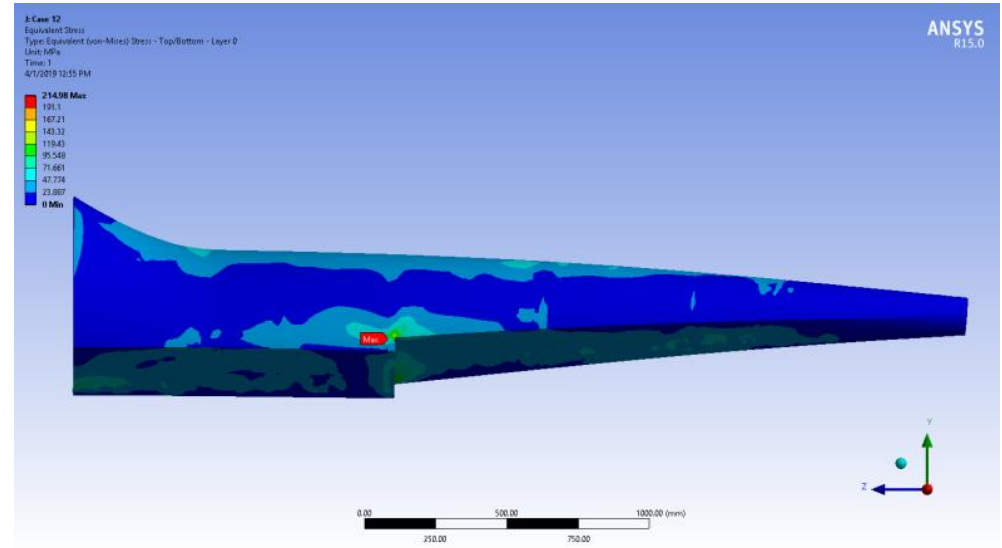

Fig. 13. Maximum stress on carbon fiber fabric.

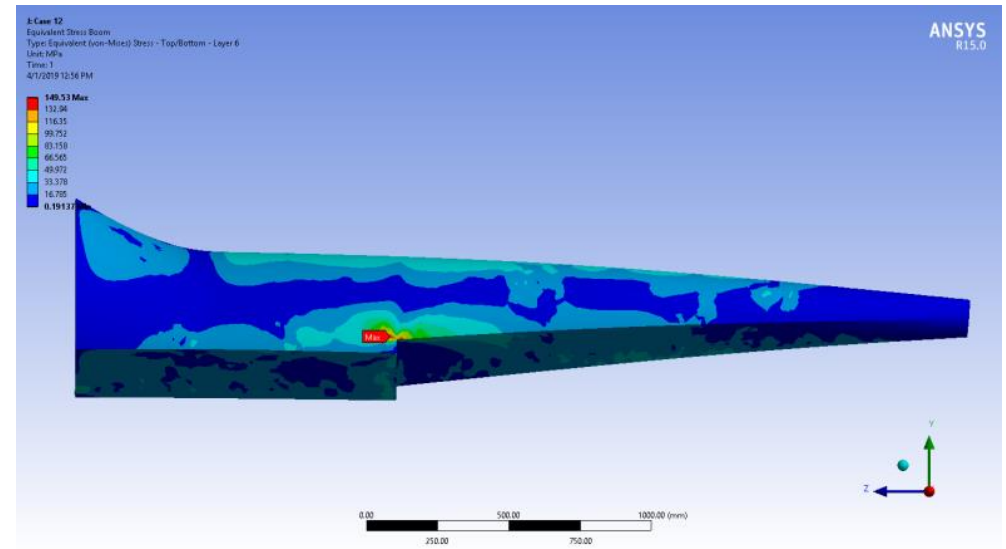

Fig. 14. Maximum stress on glass fiber fabric.

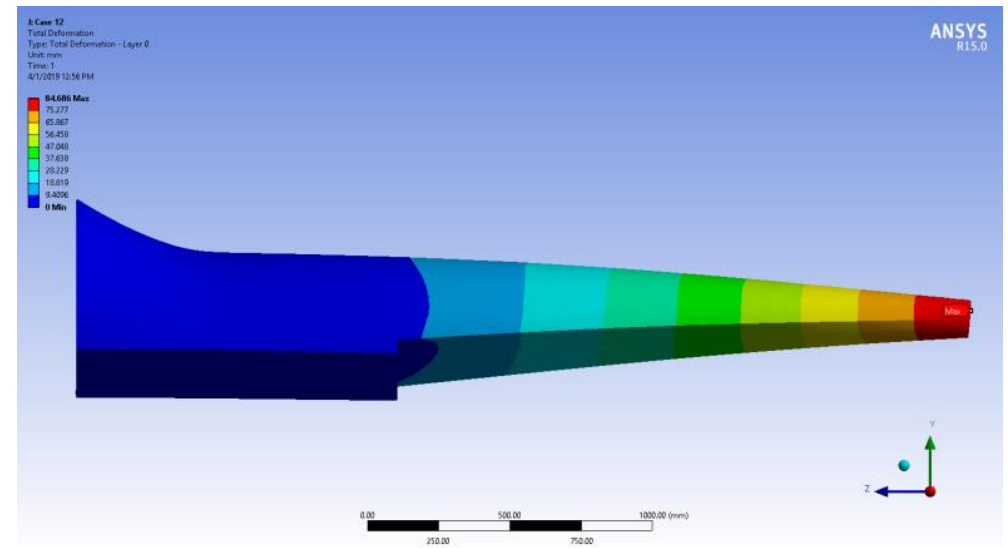

Fig. 15. Maximum displacement.

\section{Discussions}

According to Table 1, the maximum stress of the carbon fiber and glass fiber used in this research are 395 $\mathrm{MPa}$ and $160 \mathrm{MPa}$ respectively. Anyway, section 5 of ASTM F2245 clearly indicated that an ultimate load factor of safety of 1.5 must be used. Then the maximum allowable stress in carbon and glass fiber are 263 and $106 \mathrm{MPa}$ respectively. Figure 16 compares the maximum stress in carbon and glass fiber with the allowable stress of each fiber type. 


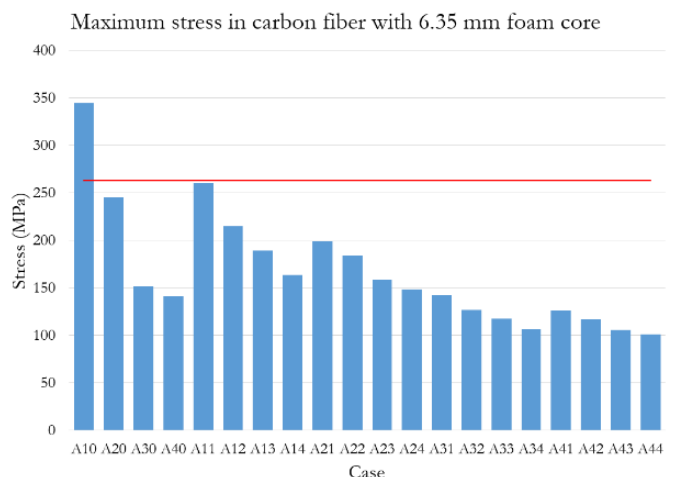

(a) Max. stress in carbon fiber of subgroup A

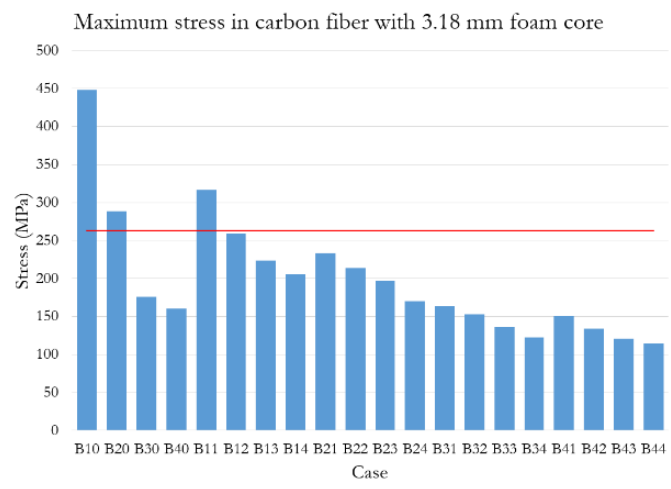

(c) Max. stress in carbon fiber of subgroup B

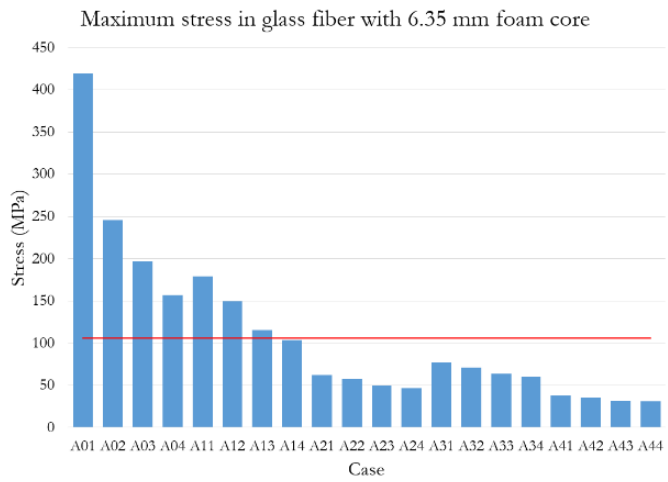

(b) Max. stress in glass fiber of subgroup A

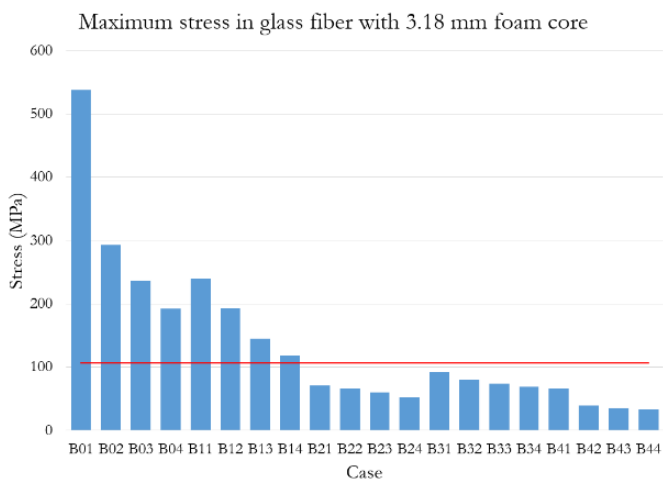

(d) Max. stress in glass fiber of subgroup B

Fig. 16. Maximum stress in carbon fiber, glass fiber in subgroups A and B compare to allowable limit.

The relationship between maximum stress in each type of fiber and no. of carbon plies and no. of glass plies can be plotted in surface plot as shown in Fig. 17. The contour plots were shown in Fig. 18.

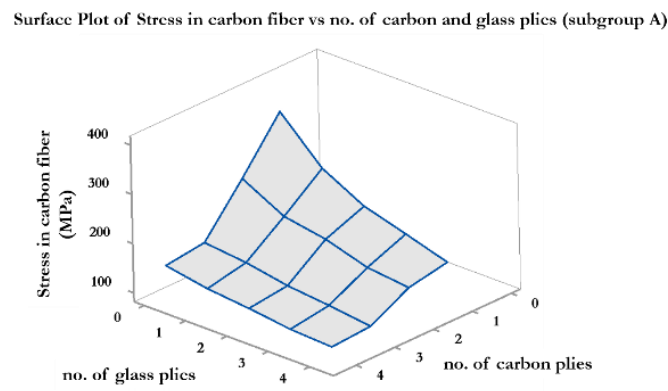

(a) Surface plot of max. stress in carbon fiber vs no. of carbon and glass plies (subgroup A)

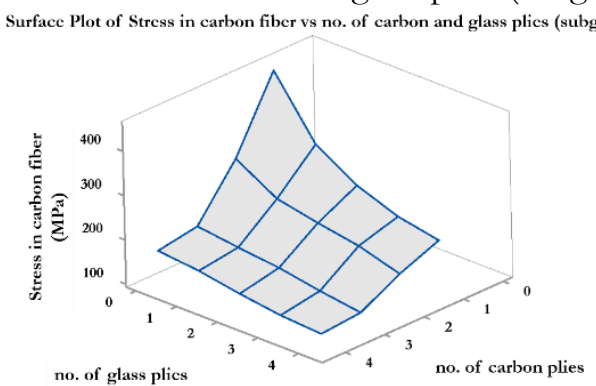

(c) Surface plot of max. stress in carbon fiber vs no. of carbon and glass plies (subgroup B)

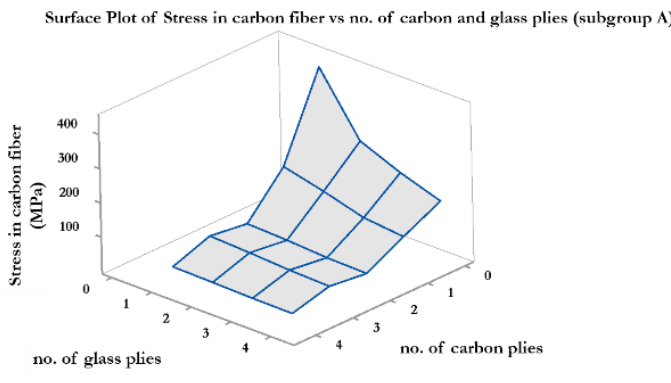

(b) Surface plot of max. stress in glass fiber vs no. of carbon and glass plies (subgroup A)

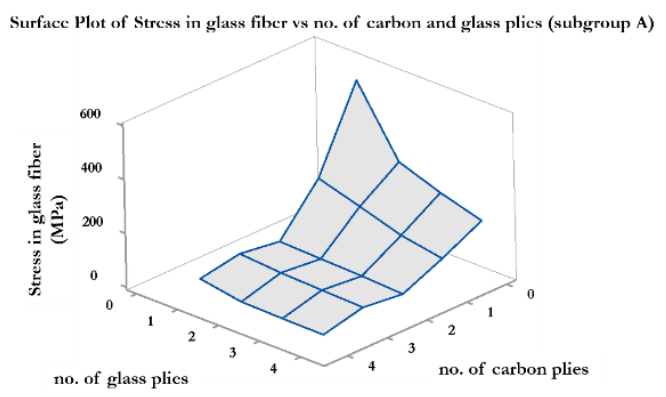

(d) Surface plot of max. stress in carbon fiber vs no. of carbon and glass plies (subgroup B)

Fig. 17. Surface plot of maximum stress in carbon and fiber vs no. of carbon and glass plies. 


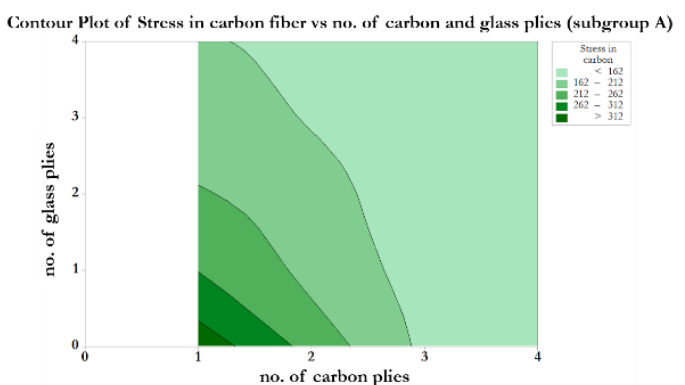

(a) Contour plot of max. stress in carbon fiber vs no. of carbon and glass plies (subgroup A) Contour Plot of Stress in carbon fiber vs no. of carbon and glass plics (subgroup $B$ )
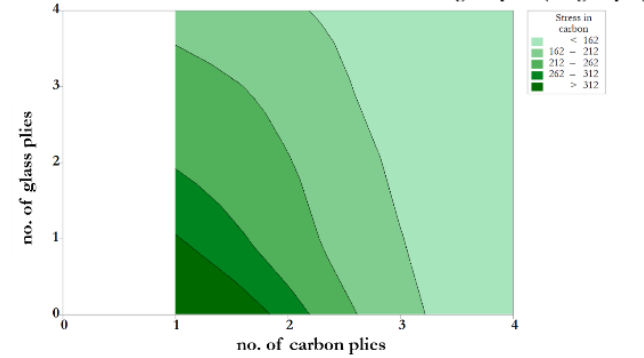

(c) Contour plot of max. stress in carbon fiber vs no. of carbon and glass plies (subgroup B)

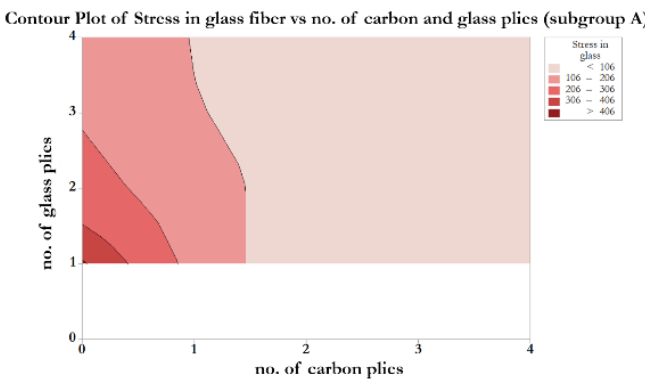

(b) Contour plot of max. stress in glass fiber vs no. of carbon and glass plies (subgroup A)

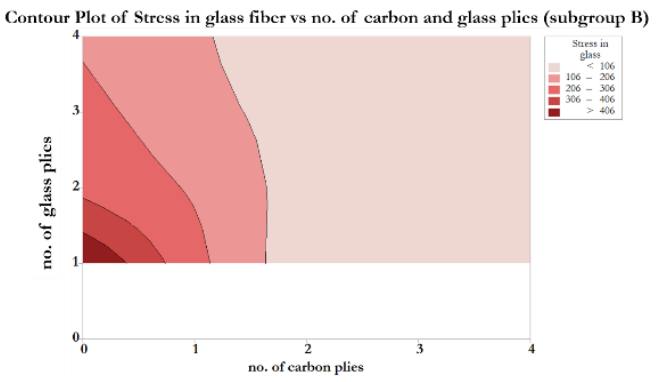

(d) Contour plot of max. stress in carbon fiber vs no. of carbon and glass plies (subgroup B)

Fig. 18. Contour plot of maximum stress in carbon and fiber vs no. of carbon and glass plies.

From Table 6, Fig. 16 to 18, there are many possibility in laminate ply patterns which the maximum stress in both carbon and glass fiber are not exceeded the allowable stress. For finding the best candidate, two criteria were applied to result. These are, weight and cost. Using these constraints, the candidate with minimum weight and cost will be selected for manufacturing. The list of candidates is shown in Table 7.

Table 7. The list of laminate ply pattern candidates.

\begin{tabular}{lcccc}
\hline Case & $\begin{array}{c}\text { Max. stress in } \\
\text { Carbon fiber } \\
\mathbf{( M P a )}\end{array}$ & $\begin{array}{c}\text { Max. stress } \\
\text { in Glass } \\
\text { fiber } \\
\mathbf{( M P a )}\end{array}$ & $\begin{array}{c}\text { Weight } \\
\mathbf{( k g )}\end{array}$ & $\begin{array}{c}\text { Cost } \\
\text { (USD) }\end{array}$ \\
\hline A30 & 151.87 & - & 6.96 & 515.50 \\
A14 & 163.55 & 103.53 & 10.81 & 359.44 \\
A21 & 199.61 & 62.26 & 7.08 & 430.38 \\
B30 & 175.75 & - & 5.99 & 439.41 \\
B21 & 233.40 & 71.40 & 6.12 & 354.29 \\
B22 & 214.13 & 65.53 & 7.92 & 361.38 \\
\hline
\end{tabular}

The candidates with minimum weight are case B30, B21 and A30. And the candidates with minimum cost are case B21, A14 and B22. It is clearly shown that the B21 have a good balance between weight and cost with maximum stress in both carbon and glass fiber within the allowable limit.

\section{Conclusions}

Although, the strength of the aircraft afterbody increase significantly with increasing number of carbon fiber layer and many advantages of the the carbon-fiber composites over the glass-fiber composites, but the cost aspects have to mentioned along with the strength of the structure. With the hybrid carbon/glass fiber composites, the balance between strength, weight and cost can be achieved.

While the stress of the carbon and glass fiber in the structure are within the safety limit, the results show that the weight is minimum in case B30 with $\left[( \pm 45)_{C}(0 / 90)_{C}( \pm 45)_{C} \bar{D}\right]_{S}$ laminate ply pattern with $3.18 \mathrm{~mm}$ 
foam core. The minimum cost occur in case B21 with $\left[( \pm 45)_{C}(0 / 90)_{C}( \pm 45)_{G} \bar{D}\right]_{S}$ laminate ply pattern. The latter case is a good compromise since the weight increased only $2 \%$ with $19 \%$ in cost reduction.

However, the physical prototype must be tested according to ASTM F2245 Standard to ensure airworthiness and safety operation before conducting the first flight.

\section{Acknowledgements}

I would also like to show my gratitude to Assoc.Prof.Sinchai Chinvorarat, Department of Mechanical and Aerospace Engineering, King Mongkut University of Technology North Bangkok for sharing his wisdom, providing ASTM F2245 and computational resources.

The research was a part of the project "Seaplane Ability Enhancement for Patrol and Commercial" and partially supported by project "Performance and Components Standard Test of a Two-Seater Seaplane for Airworthiness Certification" supported by Thailand Research Fund (TRF) under contract no. RDG5950153 and RDG5950154, respectively.

\section{References}

[1] S. Gudmundsson, General Aviation Aircraft Design: Applied Methods and Procedures. ButterworthHeinemann, 2013.

[2] F. A. A. (2004). Seaplane, Skiplane, and Float/Ski Equipped Helicopter Operations Handbook: FAA-H-808323 [Online]. Available: https://www.faa.gov/regulations_policies/handbooks_manuals/aviation/ seaplane_handbook/ [Accessed: 25 November 2017].

[3] F. A. A. (2016). Pilot's Handbook of Aeronautical Knowledge: FAA-H-8083-25B [Online]. Available: https://www.faa.gov/regulations_policies/handbooks_manuals/aviation/phak/ [Accessed: 25 November 2017].

[4] A. L. C. Leyva, "Seaplane conceptual design and sizing," Ph.D. dissertation, University of Glasgow, 2012.

[5] B. Husa. Stepped Hull Development for Amphibious Aircraft_Orion Technologies, Aerospace Design and Engineering [Online]. Available: http://citeseerx.ist.psu.edu/viewdoc/download?doi $=10.1 .1 .455 .7775 \& \mathrm{rep}=$ rep1\&type $=$ pdf [Accessed: 16 November 2017].

[6] W. C. Hugli, Jr. and W. C. Axt, "Hydrodynamic investigation of a series of hull models suitable for small flying boats and amphibians," National Advisory Committee for Aeronautics, Washington, DC, United States, NACA-TN-2503, 1951.

[7] L. K. Loftin, Jr., "Quest for performance - The evolution of modern aircraft," NASA History Office, NASA Scientific and Technical Information Branch, Washington, DC, United States, NASA SP-468, 1985.

[8] D. Crane, Dictionary of Aeronautical Terms, 3rd ed. Washington: Aviation Supplies \& Academics, 1997, pp. 194.

[9] A. F. MacDonald and W. N. Peppler, From The Ground Up, 28th ed. Ottawa, ON, Canada: Aviation Publishers Co. Ltd., 2010, pp.10.

[10] F. A. A. (2018). Aviation Maintenance Technician Handbook - Airframe, Volume 1: FAA-H-8083-31A. [Online]. Available: https://www.faa.gov/regulations_policies/handbooks_manuals/aircraft/media/ amt_airframe_hb_vol_1.pdf [Accessed: 1 August 2018].

[11] S. K. Mazumdar, Composites Manufacturing: Materials, Product and Engineering. Florida: CRC Press, 2002.

[12] F. L. Matthew, G. A. O. Davies, D. Hitchings, and C. Soutis, Finite Element Modeling of Composite Materials and Structures. CRC Press, 2000.

[13] V. V. Vasiliev and E. V. Morozov, Mechanics and Analysis of Composite Materials, 2nd ed. Oxford, UK: Elsevier Ltd, 2007.

[14] K. Potter, An Introduction to Composite Products: Design, Development and Manufacture, 1st ed. London, UK: Chapman \& Hall, 1996.

[15] D. S. Cairns and L. A. Wood. (2009). Composite Materials for Aircraft Structures [Online]. Available: http://www.montana.edu/dcairns/documents/composites/MSUComposites2009.pdf [Accessed: 1 August 2018]. 
[16] M. Nurhaniza, M. K. A. Ariffin, A. Ali, F. Mustapha, and A. W. Noraini, "Finite Element Analysis of Composites Materials for Aerospace Applications," in $9^{\text {th }}$ National Symposium on Polymeric Materials., Putrajaya, Malaysia, 2009.

[17] D. A. Day. Composites and Advanced Materials [Online]. Available: http://www.centennialofflight.gov/ essay/Evolution_of_Technology/composites/Tech40.htm [Accessed: 1 August 2018].

[18] F. Elaldi, "An overview for structural health monitoring of composites in aerospace applications," in 2nd International Conference on Recent Advances in Space Technologies, Istanbul, Turkey, 2005, pp. 309-314.

[19] A. Quilter. Composites in Aerospace Applications [Online]. Available: https://ihsmarkit.com/pdf/ Composites-Aerospace-Applications-whitepaper_264558110913046532.pdf [Accessed: 1 August 2018].

[20] M. C. Y. Niu, Airframe Structural Design, 2nd ed. California: Adaso/Adastra Engineering Center, 1999.

[21] F. Mili and B. Necib, "The effect of stacking sequence on the impact-induced damage in crossply Eglass/epoxy composites plates," Archive of Applied Mechanics, vol. 79, no. 11, pp. 1019-1031, Nov. 2009.

[22] P. D. Mangalgiri, "Composite materials for aerospace applications," Bulletin of Materials Science, vol. 22, no. 3, pp. 657-664, May 1999.

[23] J. Summerscales and D. Short, "Carbon fiber and glass fiber hybrid reinforced plastics," Composites, vol. 9, no. 3, pp. 157-166, Jul. 1978.

[24] L. Mishnaevsky, Jr., "Composite materials for wind energy applications: micromechanical modelling and future directions," Computational Mechanics, vol. 50, no. 2, pp. 195-207, Aug. 2012.

[25] P. W. Manders and M. G. Bader, "The strength of hybrid glass/carbon fiber composites. Part 1 Failure strain enhancement and failure mode," Journal of Materials Science, vol. 16, pp. 2233-2245, 1981.

[26] Y. Shan, K. F. Lai, K. T. Wan, and K. Liao, "Static and dynamic fatigue of glass-carbon hybrid composites in fluid environment," Journal of Composite Materials, vol. 36, no. 02, pp. 159-72, 2002.

[27] Y. Shan and K. Liao, "Environmental fatigue of unidirectional glass-carbon fiber reinforced hybrid composite," Composite Part B: Engineering, vol. 32, no. 4, pp. 355-363, 2001.

[28] G. Belingardi and M. P. Cavatorta, "Bending fatigue stiffness and strength degradagion in carbon-glass epoxy hybrid laminates: Cross-ply vs. angle-ply speciments," International Journal of Fatigue, vol. 28, no. 8, pp. 815-825, 2006.

[29] M. P. Cavatorta, "A Comparative study if the fatigue and post-fatigue behavior of carbon-glass/epoxy hybrid RTM and hand lay-up composites," Journal of Materials Science, vol. 42, no. 20, pp. 8636-8644, Oct. 2007.

[30] P. Y. Hung, K. T. Lau, L. K. Cheng, J. Leng, and D. Hui, "Impact response of hybrid carbon/glass fiber reinforced polymer composites designed for engineering applications," Composites Part B: Engineering, vol. 133, pp. 86-90, Jan. 2018.

[31] J. Zhang, K. Chaisombat, S. He, and C. H. Wang, "Hybrid composite laminates reinforced with glass/carbon woven fabrics for light weight load bearing structures," Materials and Design, vol. 36, pp. 75-80, 2012.

[32] J. Zhang, K. Chaisombat, S. He, and C. H. Wang, "Glass/carbon fiber hybrid composite laminates for structural applications in automotive vehicles," Sustainable Automotive Technologies, vol. 2012, pp. 69-74, 2012.

[33] R. T. D. Prabhakaran, T. L. Andersen, C. M. Markussen, B. Madsen, and H. Lilholt, "Tensile and compression properties of hybrid composites - A comparative study," in 19th International Conference on Composite Materials., Montreal, Canada, 2013, pp. 1029-1035.

[34] G. Dai and L. Mishnaevsky, Jr., "Fatigue of hybrid glass/carbon composites: 3D computational studies," Composites Science and Technology, vol. 94, pp. 71-79, Apr. 2014.

[35] C. Dong, "Uncertainties in flexural strength of carbon/glass fiber reinforced hybrid epoxy composites," Composites Part B: Engineering, vol. 98, pp.176-181, Aug. 2016.

[36] S. C. Buddi, P. P. Prasanthi, and P. Srikanth, "Mechanical properties of fiber reinforced composites using finite element method," International Journal of Mechanical Engineering and Robotics Research, vol. 4, no. 1, pp. 80-90, 2015.

[37] V. Dulgheru, B. Viorel, and G. Marin, "Some research on FEA of composite materials," Mechanical Testing and Diagnosis, vol. 3, pp. 79-85, 2012.

[38] W. X. Ren, S. E. Fang, and M. Y. Deng, "Response surface-based FEM updating using structural static response," Journal of Engineering Mechanics, vol. 137, no. 4, pp. 248-257, 2011. 
[39] K. Venkatesh, M. Kannan, and J. Kuberan, "Optimization of truck chassis of support stiffness to improve the fundamental natural frequencies," Journal of Mechanical and Civil Engineering, vol. 3, pp. 614, 2014.

[40] I. Cayiroglu and R. Kilic, "Wing aerodynamic optimization by using genetic algorithm and ANSYS," in 3rd International Conference on Computational and Experimental Science and Engineering., Antalya, Kemer, Turkey, 2016.

[41] M. Ozroy and C. Kurmaz, "An optimization study of a hydraulic gear pump cover with finite element method," in 3rd International Conference on Computational and Experimental Science and Engineering., Antalya, Kemer, Turkey, 2016.

[42] J. D. Anderson, Jr., Aircraft performance and Design, New York: McGraw-Hill, 1999.

[43] T. Benson. (2006). Aerodynamic Center - ac [Online]. Available: https://www.grc.nasa.gov/www/k12/airplane/ac.html [Accessed: 25 November 2017]. 